\title{
Smartphone-assisted spatial data collection improves geographic information quality: pilot study using a birth records dataset
}

\author{
Xiaohui Xu, ${ }^{1}$ Hui Hu, ${ }^{2}$ Sandie Ha, ${ }^{2}$ Daikwon Han ${ }^{1}$ \\ ${ }^{1}$ Department of Epidemiology and Biostatistics, Texas A\&M University, College Station, TX; \\ ${ }^{2}$ Department of Epidemiology, University of Florida, Gainesville, FL, USA
}

\begin{abstract}
It is well known that the conventional, automated geocoding method based on self-reported residential addresses has many issues. We developed a smartphone-assisted aerial image-based method, which uses the Google Maps application programming interface as a spatial data collection tool during the birth registration process. In this pilot
\end{abstract}

Correspondence: Xiaohui Xu, Department of Epidemiology and Biostatistics, School of Public Health, Texas A\&M University, 205A SRPH Administration Building, MS 1266, 212 Adriance Lab Road, 77843-1266 College Station, TX, USA.

Tel: +1.979 .4369500 - Fax: +1.979 .4581877 .

E-mail: xiaohui.xu@sph.tamhsc.edu

Key words: Positional accuracy; Geocode; Vital statistics; Bias; Environmental epidemiology.

Contributions: $\mathrm{XX}$, study design, data analyzing and manuscript writing and reviewing; $\mathrm{HH}, \mathrm{SH}, \mathrm{DH}$, data collection and analyzing, reference search, manuscript writing and reviewing.

Funding: this work was supported by Grant Number K01ES019177 from the National Institute of Environmental Health Sciences (NIEHS), Research Triangle Park, NC, USA.

Ethic approval: the research protocol for this study was approved by the Institutional Review Board at the University of Florida and the Florida Department of Health, Tallahassee, FL, USA.

Acknowledgements: the data were provided by the Bureau of Vital Statistics, Florida Department of Health (DOH), Tallahassee, FL, USA. All conclusions are the authors' own and do not necessarily reflect the opinion of the NIEHS or the Florida DOH.

Received for publication: 12 April 2016.

Revision received: 15 August 2016.

Accepted for publication: 1 September 2016.

(C) Copyright X. Xu et al., 2016

Licensee PAGEPress, Italy

Geospatial Health 2016; 11:482

doi:10.4081/gh.2016.482

This article is distributed under the terms of the Creative Commons Attribution Noncommercial License (CC BY-NC 4.0) which permits any noncommercial use, distribution, and reproduction in any medium, provided the original author(s) and source are credited. study, we have tested whether the smartphone-assisted method provides more accurate geographic information than the automated geocoding method in the scenario when both methods can get the address geocodes. We randomly selected 100 well-geocoded addresses among women who gave birth in Alachua county, Florida in 2012. We compared geocodes generated from three geocoding methods: i) the smartphone-assisted aerial image-based method; ii) the conventional, automated geocoding method; and iii) the global positioning system (GPS). We used the GPS data as the reference method. The automated geocoding method yielded positional errors larger than $100 \mathrm{~m}$ among $29.3 \%$ of addresses, while all addresses geocoded by the smartphoneassisted method had errors less than $100 \mathrm{~m}$. The positional errors of the automated geocoding method were greater for apartment/condominiums compared with other dwellings and also for rural addresses compared with urban ones. We conclude that the smartphone-assisted method is a promising method for perspective spatial data collection by improving positional accuracy.

\section{Introduction}

Geocoded, vital statistics birth records have been widely used to examine the potential adverse effects of environmental exposures during pregnancy on pregnancy and birth outcomes, including low birth weight, preterm delivery, small for gestational age (Dadvand et al., 2012; Metcalfe et al., 2011; Sapkota et al., 2012; Shah and Balkhair, 2011; Stieb et al., 2012; Strand et al., 2011), congenital anomalies (Vrijheid et al., 2011), pregnancy complications such as hypertensive disorders of pregnancy (Hu et al., 2014), and gestational diabetes mellitus (Hu et al., 2015). A wide range of environmental factors have been investigated in previous studies, including air pollution (Hu et al., 2014, 2015; Sapkota et al., 2012; Shah and Balkhair, 2011; Stieb et al., 2012; Vrijheid et al., 2011), temperature (Strand et al., 2011), greenness (Dadvand et al., 2012), built environment (Hystad et al., 2014; Miranda et al., 2012), and other neighbourhood-level factors such as income, education, and racial residential segregation (Anthopolos et al., 2014; Metcalfe et al., 2011). These studies provide important evidence in this field. However, geocoded information in the vital statistic birth records using the traditional automated, geocoding method based on self-reported residential addresses has many issues including missing geocode data and positional errors of geocoded addresses.

The issues regarding positional accuracy of geocoded addresses have drawn much attention and recent studies suggest that potential errors cannot be ignored when using geocoding methods in epidemiologic studies (Cayo and Talbot, 2003; Hurley et al., 2003; Whitsel et al., 2006). The positional errors seen with geocoding can have substantial 
impacts on many salient factors underlying environmental epidemiologic studies (Jacquez, 2012), including exposure estimates (Zandbergen, 2007), health access analysis (Frizzelle et al., 2009; McLafferty et al., 2012), disease cluster detection (Jacquez and Rommel, 2009; Zimmerman et al., 2008), disease rates estimates (Goldberg and Cockburn, 2012), and spatial weights (Jacquez and Rommel, 2009). More importantly, studies have shown the heterogeneity in positional accuracy with greater geocoding errors observed in rural compared to urban areas (Cayo and Talbot, 2003; Hurley et al., 2003; Whitsel et al., 2006). These errors may cause a differential misclassification among rural and non-rural individuals and lead to biased results in epidemiologic studies (Krieger et al., 2001; Oliver et al., 2005). Alternative geocoding methods such as aerial image-based methods have been available for a long time and are usually used for improving positional accuracy of addresses in the traditional post-hoc geocoding method. The advantages of these methods have been reported by many authors (Baltsavias, 1993; Boulos, 2005; Conzelmann et al., 2005; Hild and Fritsch, 1998; Richards et al., 1999; Ward et al., 2005), but limited knowledge regarding the addresses among geographic information system technicians could significantly restrict their application in geocoding. More importantly, to our knowledge, these techniques have not been used for spatial data collection. We propose a smartphone-assisted aerial image-based method for spatial data collection during the process of birth registry. This method has many advantages including map/aerial image searching for addresses, participants' involved verification and real-time geocoding over the traditional post-hoc geocoding method (Figure 1). The prospective use of such methods has the potentials to substantially improve data quality by reducing missing values and improving the accuracy of geographic information.

In this pilot study, we aimed to examine if the smartphone-assisted, aerial image-based method provides more accurate geographic information than the post-hoc geocoding method in the scenario when both methods can obtain the geographic information of an address.

\section{Materials and Methods}

\section{Study population and geocoding by Florida Department of Health}

We obtained birth record data from the Bureau of Vital Statistics \& Office of Health Statistics and Assessment, Florida Department of Health (FDOH), Tallahassee, FL, USA. The data included all registered live births in Florida (FL), USA between January 1, 2012 and December 31, 2012 ( $n=211,437)$. The FDOH used ArcGIS 10.1 software with the topologically integrated geographic encoding and referencing (TIGER) street database from the US Census Bureau to geocode maternal residential address at delivery for all FL residents, while 1,093 births with maternal address outside FL were not geocoded. A total of 206,796 (98.3\%) women were successfully geocoded among the 210,344 women living within the state of Florida. A total of 2733 women with geocoded maternal residential addresses inside Alachua county, FL were eligible to be sampled in this study. The population of Alachua county was 251,417 (71\% urban, $29 \%$ rural) that year. From these eligible addresses, a total of 100 addresses were statistically randomly sampled using

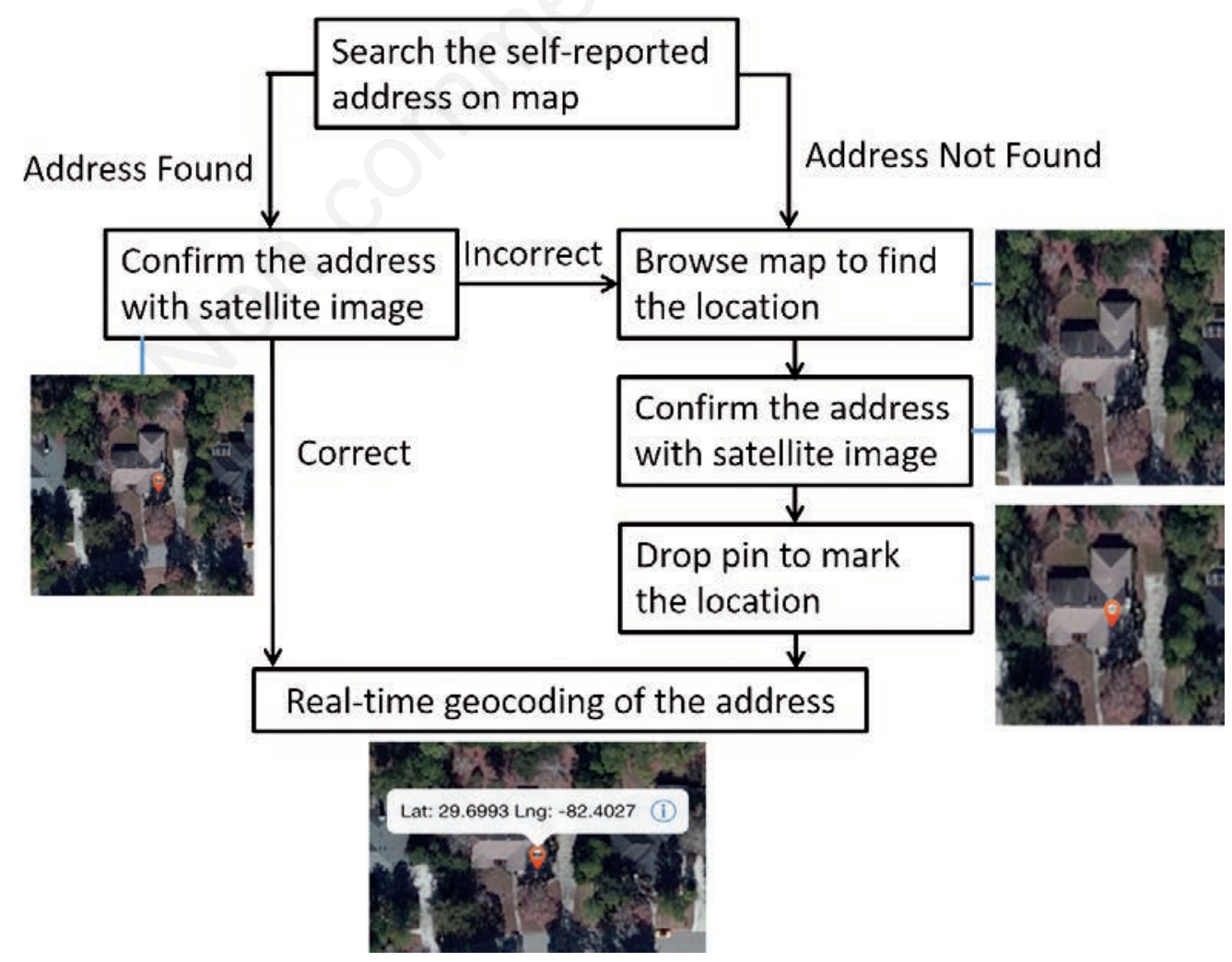

Figure 1. Illustration of a smartphone-assisted aerial image-based method for spatial data collection. 
the SURVEYSELECT procedure in SAS 9.3 (http://support.sas.com/documentation/cdl/en/statug/63962/HTML/default/viewer.htm\#statug_surveyselect_sect001.htm).

We compared geocodes generated from three geocoding methods: i) the conventional, FDOH-geocoded records using an automated, geocoding method based on the TIGER street database (https://www.census. gov/geo/maps-data/data/tiger.html) and ArcGIS (http://www.esri.com); ii) reference measures using global positioning system (GPS) receivers $5 \mathrm{~m}$ away from the sampled addresses (outside the building); and iii) the geocodes obtained from the smartphone-assisted, aerialbased method using the Google Maps application programming interface (API) (Google, 2015).

\section{Global positioning system receiver measurements}

The Garmin GPSMAP ${ }^{\circledR} 76 \mathrm{Cx}$ receiver (Garmin International Inc., Olathe, KS, USA) was used. The typical position accuracy of this receiver ranges from 3 to $5 \mathrm{~m}$, and it has been validated and widely used in many studies (Wing, 2008). In this study, GPS measurements were taken $5 \mathrm{~m}$ away from the sampled addresses (outside the building), in order to avoid direct interactions or contacts with any residents. None of the addresses located in apartment complexes have controlled access during daytime when the measurements were done. All data were collected in January 2015.

\section{The smartphone-assisted, aerial image-based method}

Besides the automated and GPS-measured geocodes, we developed and used a method built on satellite and aerial images using Google Map API (Google, 2015). Briefly, the researchers automatically search the address on the map, browse the aerial images, verify the location (i.e. simulating the process of participant-involved verification) and obtain the geocodes of the address, or the first placed pinpoint on the aerial images if the address cannot be automatically found, aligned with the centroid location of each actual address. The system then returns and records the longitude and latitude for the pinpoint. Figure 1 shows the algorithm of the smartphone-assisted, aerial image-based method for spatial data collection during participant interview. As shown, the geographic coordinates of the location will be automatically generated and collected from this proposed method so that no post-hoc data cleaning or geocoding is needed. In this pilot study, the data collectors all had background knowledge obtained through field visits to the selected addresses that served as participants.

\section{Covariates}

Information of maternal, socio-demographic status was obtained from the vital statistics dataset, including maternal age at delivery ( $<30$ or $\geq 30$ years old), race (black or non-black), education level (<high school, high school, or > high school), marital status (married or not married) and insurance types (Medicaid or non-Medicaid). In addition, housing types were categorized into two groups: apartment/condominium and others. We also categorised each address as urban or rural based on the GPS-measured geocodes using the 2013 cartographic boundary shapefiles (urban areas) from the US Census (https://www.census.gov/geo/maps-data/data/cbf/cbf_ua.html).

\section{Statistical analysis}

The geocodes measured by the GPS receiver were used as the reference in this study. Geocodes from all three different methods were based on the datum WGS84. The positional errors of the automated geocoded addresses by FDOH and the geocodes generated using the smartphone-assisted method were determined by their geodetic dis- tance (the shortest path along the ellipsoid of the Earth at sea level between two points) to the GPS-measured geocodes in meters using the GEODIST function in SAS 9.3. Descriptive statistics were generated where appropriate, and paired t-tests were used to examine the difference in positional errors between the automated geocoding method and the smartphone-assisted method. The distribution of parcel size for the addresses was generated by housing type (apartment/condominium or not). We used both regression and treebased methods to model the potential association between housing types, maternal characteristics, urbanization and the positional accuracy of the automated geocoding method. The positional errors of the automated geocoded addresses by FDOH were modelled both as continuous and dichotomous variables ( $>100 \mathrm{~m}$ or $100 \mathrm{~m}$ ). The cut-off of $100 \mathrm{~m}$ was selected because of its widely use in literatures of positional accuracy and environmental exposure assessment (Bonner et al., 2003; Gordian et al., 2006; Wu et al., 2005; Zandbergen et al., 2011). We first fitted generalized linear models for these outcomes and all covariates with the continuous outcomes log-transformed to account for its skewed distribution, and then used regression trees to further explore the potential interactions and nonlinear association between the covariates and the outcomes (James et al., 2013). The regression tree is a non-parametric method which recursively partitions the data space and fits a simple prediction model within each partition. Therefore, it can identify complex interaction and non-linear associations between the predictors and the outcome without any a priori specification. Data management was performed using SAS 9.3 and all analysis were conducted using R 3.1.2.

\section{Results}

Among the 100 randomly sampled addresses, 99 were successfully identified and geocoded using both the GPS receiver and the smartphone-assisted method. All subsequent analyses were based on the 99 successfully identified and geocoded addresses. For the one remaining address, apparent errors in the street number made it unidentifiable, so it was excluded from this study.

Table 1 shows the distribution of maternal socioeconomic status at delivery, housing and area characteristics. Most of the women living in the sampled addresses were less than 30 years old (65.66\%), NonBlack (64.65\%), had education levels greater than high school (74.75\%), married $(59.60 \%)$ or had insurance other than Medicaid (61.62\%). Approximately $30 \%$ of the housing was apartments or condominiums and approximately $14 \%$ of the addresses were located in rural areas. Table 1 also presents the geometric means of positional errors measured by both the automated geocoding method and the smartphone-assisted method. Overall, the automated geocoding method yielded a mean (geometric) positional error of $56.46 \mathrm{~m}$, while the error for the smartphone-assisted method was confined to 13.30 $\mathrm{m}$. Consistent patterns were observed in all subgroups by scociodemographic status, housing and area characteristics. In addition, the paired t-test showed significant differences between all pairs examined (all $P$ values $<0.05$ ). The distribution of parcel size by housing type is presented in Table 2.

Figure 2 compares the positional errors between the automated geocoding method and the smartphone-assisted method. All aerial image geocoded locations fell within $100 \mathrm{~m}$ away from the true location with around $94 \%$ of them within $50 \mathrm{~m}$. However, only around $70 \%$ of the automated geocoded addresses were within $100 \mathrm{~m}$ of the true location with 52 and $9 \%$ having errors less than 50 and $10 \mathrm{~m}$, respec- 
tively. When stratified (Table 3), we found higher proportions of misclassified addresses for apartment/condominiums compared with other housing types (67 vs 13\% of addresses with positional errors greater than $100 \mathrm{~m}$ ) and when comparing addresses located in rural areas to those located in urban areas, the outcome was 43 vs $27 \%$, respectively, when the automated geocoding method was used for geocoding. In addition, there was no address with $>100$ m positional errors with the new mobile-assisted method.

Table 4 shows the results of the generalized linear models used to examine the potential association between the positional errors of the automated geocoding method and covariates. The continuous model showed that the housing type of apartment/condominium was associated with a 1.59 [95\% confidence interval (CI): 1.07, 2.12] increase in the log-transformed positional error. In addition, the logistic regression model found that addresses of the apartment/condominium housing type compared with those located in rural areas had 64.54 (95\% CI: $14.94,409.55)$ and 9.66 (95\% CI: 1.79, 64.93), respectively, times the odds of being automatically geocoded with positional errors $>100 \mathrm{~m}$, respectively. Nonblack women's addresses were also found to be significantly associated with an increased odds ratio (OR: 7.08, 95\% CI: $1.25,51.90$ ) of having positional errors greater than $100 \mathrm{~m}$ when using the automated geocoding method.

Figure 3 presents the covariates significantly associated with positional errors of the automated geocoding method from the regression trees analyses. The housing type was significant in both models on continuous and dichotomous outcomes and urbanity was shown as an important predictor for positional errors of the automated geocoding method among the addresses that were not apartment/condominiums.

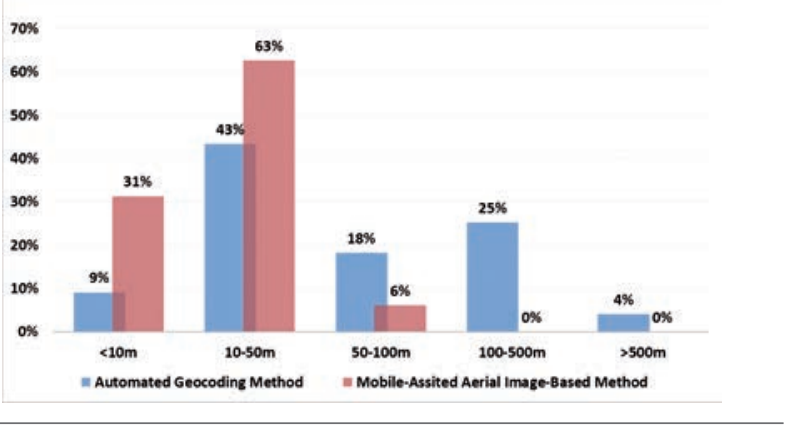

Figure 2. The positional errors between the automated geocoding method and the smartphone-assisted method.

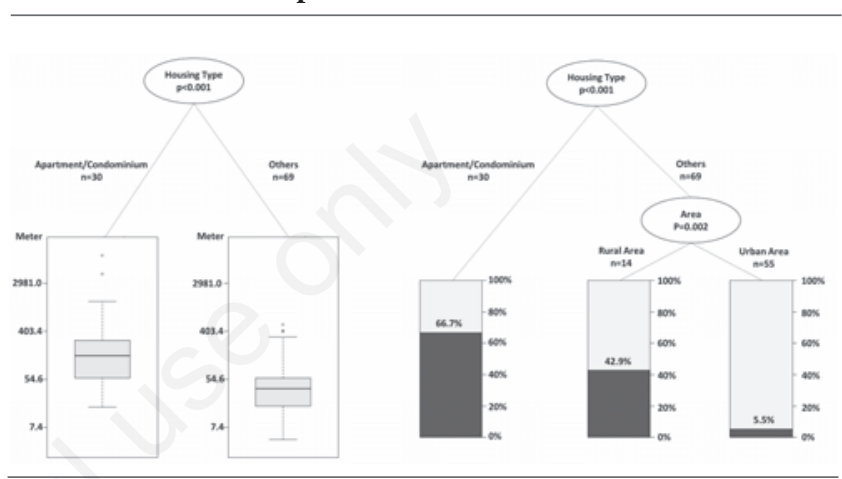

Figure 3. Covariates significantly associated with positional errors of the automated geocoding method.

Table 1. Geometric means of positional errors by maternal scociodemographic status and housing and area characteristics.

\begin{tabular}{|c|c|c|c|c|c|}
\hline Parameter & $\mathbf{N}$ & $\%$ & $\begin{array}{c}\text { Pos } \\
\text { geo } \\
\begin{array}{c}\text { Automated geocoding } \\
\text { method }\end{array}\end{array}$ & $\begin{array}{l}\text { r (m), } \\
\text { in } \pm \text { SD } \\
\text { Mobile-assisted aerial } \\
\text { image-based method }\end{array}$ & $\mathbf{P}$ \\
\hline Total & 99 & 100.00 & $56.46 \pm 3.81$ & $13.30 \pm 3.18$ & $<0.001$ \\
\hline $\begin{array}{l}\text { Age at delivery (years) } \\
\quad<30 \\
\quad \geq 30\end{array}$ & $\begin{array}{l}65 \\
34\end{array}$ & $\begin{array}{l}65.66 \\
34.34\end{array}$ & $\begin{array}{l}58.22 \pm 3.98 \\
53.25 \pm 3.56\end{array}$ & $\begin{array}{l}11.92 \pm 3.18 \\
16.41 \pm 3.14\end{array}$ & $\begin{array}{l}<0.001 \\
<0.001\end{array}$ \\
\hline $\begin{array}{l}\text { Race } \\
\text { Black } \\
\text { Non-black }\end{array}$ & $\begin{array}{l}35 \\
64\end{array}$ & $\begin{array}{l}35.35 \\
64.65\end{array}$ & $\begin{array}{l}45.57 \pm 3.44 \\
63.48 \pm 4.05\end{array}$ & $\begin{array}{l}10.15 \pm 3.60 \\
15.43 \pm 2.90\end{array}$ & $\begin{array}{l}<0.001 \\
<0.001\end{array}$ \\
\hline $\begin{array}{l}\text { Education } \\
<\text { High school } \\
\text { High school } \\
>\text { High school }\end{array}$ & $\begin{array}{c}17 \\
8 \\
74\end{array}$ & $\begin{array}{c}17.17 \\
8.08 \\
74.75\end{array}$ & $\begin{array}{l}55.33 \pm 4.24 \\
59.88 \pm 4.39 \\
56.36 \pm 3.74\end{array}$ & $\begin{array}{c}10.83 \pm 3.43 \\
9.47 \pm 4.58 \\
14.47 \pm 3.01 \\
\end{array}$ & $\begin{array}{l}<0.001 \\
0.031 \\
<0.001\end{array}$ \\
\hline $\begin{array}{l}\text { Marital status } \\
\text { Married } \\
\text { Not married }\end{array}$ & $\begin{array}{l}59 \\
40\end{array}$ & $\begin{array}{l}59.60 \\
40.40\end{array}$ & $\begin{array}{l}67.20 \pm 3.83 \\
43.67 \pm 3.68\end{array}$ & $\begin{array}{l}13.76 \pm 3.36 \\
12.67 \pm 2.96\end{array}$ & $\begin{array}{l}<0.001 \\
<0.001\end{array}$ \\
\hline $\begin{array}{l}\text { Insurance } \\
\text { Medicaid } \\
\text { Non-Medicaid }\end{array}$ & $\begin{array}{l}38 \\
61 \\
\end{array}$ & $\begin{array}{l}38.38 \\
61.62\end{array}$ & $\begin{array}{l}48.90 \pm 3.61 \\
61.75 \pm 3.95\end{array}$ & $\begin{array}{l}10.72 \pm 3.51 \\
15.22 \pm 2.95\end{array}$ & $\begin{array}{l}<0.001 \\
<0.001\end{array}$ \\
\hline $\begin{array}{l}\text { Housing type } \\
\text { Apartment/condominium } \\
\text { Other }\end{array}$ & $\begin{array}{l}30 \\
69\end{array}$ & $\begin{array}{l}30.30 \\
69.70\end{array}$ & $\begin{array}{c}151.09 \pm 4.06 \\
36.80 \pm 2.90\end{array}$ & $\begin{array}{c}7.91 \pm 3.28 \\
16.68 \pm 2.93\end{array}$ & $\begin{array}{l}<0.001 \\
<0.001\end{array}$ \\
\hline $\begin{array}{l}\text { Area } \\
\text { Urban area } \\
\text { Rural area }\end{array}$ & $\begin{array}{l}85 \\
14\end{array}$ & $\begin{array}{l}85.86 \\
14.14\end{array}$ & $\begin{array}{l}54.97 \pm 3.85 \\
66.40 \pm 3.69\end{array}$ & $\begin{array}{l}12.94 \pm 3.14 \\
15.72 \pm 3.56\end{array}$ & $\begin{array}{c}<0.001 \\
0.021\end{array}$ \\
\hline
\end{tabular}

SD, standard deviation. 


\section{Discussion}

Using GPS receivers as the reference measure for true location, we compared the positional errors of the automated geocoding method used by FDOH and the smartphone-assisted geocoding method. The conventional automated geocoding method has substantial deficiencies in positional accuracy with approximately $30 \%$ of the geocoded addresses having positional errors exceeding $100 \mathrm{~m}$; this is a significant methodologic shortcoming in many settings of environmental epi- demiologic studies (Griffith et al., 2007; Zandbergen, 2008). The positional errors of the automated geocoding method observed in this study are comparable to previous research conducted in the states of Iowa, New York and Texas, from where $21-28 \%$ of the automated geocoded addresses over $100 \mathrm{~m}$ have been reported (Bonner et al., 2003; Ward et al., 2005; Zhan et al., 2006). More importantly, our study shows that such errors are not randomly distributed given the association observed between positional errors and housing type and urbanity. In addition to the urban-rural heterogeneity of positional errors reported from previous studies (Cayo and Talbot, 2003; Hurley et al., 2003;

Table 2. Distribution of parcel size (square meters) by housing type.

\begin{tabular}{|c|c|c|c|c|c|c|}
\hline Housing type & $\mathbf{N}$ & Median & Mean & SD & Quartile 1 & Quartile 3 \\
\hline Apartment/condominium & 30 & $40,984.13$ & $57,131.70$ & $62,680.05$ & 1627.07 & $104,800.82$ \\
\hline Others & 69 & 1104.41 & $18,958.34$ & $48,402.67$ & 730.78 & 7265.93 \\
\hline Total & 99 & 1390.65 & $24,742.18$ & $52,294.61$ & 801.27 & $20,234.57$ \\
\hline
\end{tabular}

SD, standard deviation.

Table 3. Positional errors by housing type and area.

\begin{tabular}{|c|c|c|c|c|c|}
\hline \multirow[t]{2}{*}{ Housing type/area } & \multirow[t]{2}{*}{$\begin{array}{l}\text { Total number } \\
\text { of addresses }\end{array}$} & \multicolumn{2}{|c|}{$\begin{array}{l}\text { Automated } \\
\text { geocoding method }\end{array}$} & \multicolumn{2}{|c|}{$\begin{array}{l}\text { Mobile-assisted aerial } \\
\text { image-based method }\end{array}$} \\
\hline & & $\begin{array}{l}\text { Addresses with } \\
\text { errors }>100 \mathrm{~m}\end{array}$ & $\%(95 \% \mathrm{CI})$ & $\begin{array}{c}\text { Addresses with } \\
\text { errors }>100 \mathrm{~m}\end{array}$ & $\%\left(95 \% \mathrm{CI}^{*}\right)$ \\
\hline Apartment or condominium & 30 & 20 & $66.67(49.80,83.54)$ & 0 & - \\
\hline Other & 69 & 9 & $13.04(5.10,20.99)$ & 0 & - \\
\hline Urban area & 85 & 23 & $27.06(17.61,36.50)$ & 0 & - \\
\hline Rural area & 14 & 6 & $42.86(16.93,68.78)$ & 0 & - \\
\hline
\end{tabular}

Cl, confidence interval.

Table 4. Associations between positional error of automated geocoding method by Florida Department of Health and maternal socioeconomic status and housing characteristics.

\begin{tabular}{|c|c|c|}
\hline Parameter & $\begin{array}{c}\text { Continuous } \\
\text { (Log-transformed), } \\
\beta(95 \% \mathrm{CI})\end{array}$ & $\begin{array}{c}\text { Dichotomous } \\
(>100 \mathrm{~m} v s \leq 100 \mathrm{~m}), \\
\text { OR }(95 \% \mathrm{CI})\end{array}$ \\
\hline $\begin{array}{l}\text { Age at delivery (years) } \\
\quad<30 \\
\quad \geq 30\end{array}$ & $\begin{array}{c}\text { Reference } \\
-0.25(-0.79,0.30)\end{array}$ & $\begin{array}{c}\text { Reference } \\
0.89(0.22,3.70)\end{array}$ \\
\hline $\begin{array}{l}\text { Race } \\
\text { Black } \\
\text { Non-black }\end{array}$ & $\begin{array}{c}\text { Reference } \\
0.32(-0.36,1.00)\end{array}$ & $\begin{array}{c}\text { Reference } \\
7.08(1.25,51.90)\end{array}$ \\
\hline $\begin{array}{l}\text { Education } \\
\quad<\text { High school } \\
\text { High school } \\
>\text { High school }\end{array}$ & $\begin{array}{c}\text { Reference } \\
0.37(-0.54,1.28) \\
0.38(-0.40,1.15)\end{array}$ & $\begin{array}{c}\text { Reference } \\
4.92(0.50,53.51) \\
0.63(0.08,5.09)\end{array}$ \\
\hline $\begin{array}{l}\text { Marital status } \\
\text { Married } \\
\text { Not married } \\
\end{array}$ & $\begin{array}{c}\text { Reference } \\
-0.43(-1.09,0.23)\end{array}$ & $\begin{array}{c}\text { Reference } \\
0.77(0.14,4.23)\end{array}$ \\
\hline $\begin{array}{l}\text { Insurance } \\
\text { Medicaid } \\
\text { Non-Medicaid }\end{array}$ & $\begin{array}{c}\text { Reference } \\
0.02(-0.66,0.69)\end{array}$ & $\begin{array}{c}\text { Reference } \\
0.42(0.08,2.09)\end{array}$ \\
\hline $\begin{array}{l}\text { Housing type } \\
\text { Apartment/condominium } \\
\text { Other }\end{array}$ & $\begin{array}{c}\text { Reference } \\
1.59(1.07,2.12)\end{array}$ & $\begin{array}{c}\text { Reference } \\
64.54(14.94,409.55)\end{array}$ \\
\hline $\begin{array}{l}\text { Area } \\
\text { Urban area } \\
\text { Rural area } \\
\end{array}$ & $\begin{array}{c}\text { Reference } \\
0.62(-0.12,1.35)\end{array}$ & $\begin{array}{c}\text { Reference } \\
9.66(1.79,64.93) \\
\end{array}$ \\
\hline
\end{tabular}

CI, confidence interval; OR, odds ratio. 
Whitsel et al., 2006), we observed even larger heterogeneity among addresses referring to apartment/condominiums. These non-randomly distributed errors may lead to a differential misclassification bias that will greatly influence the validity of studies based on these automated geocoding data.

In addition, we found that the smartphone-assisted geocoding method may substantially increase the positional accuracy compared with traditional geocoding. Different from some previous studies which used the geocodes by the aerial image as the true location gold standard (Schootman et al., 2007), we regarded aerial image as a potential method for address location verification during the spatial data collection. Although the aerial image substantially improved positional accuracy, it still had slightly discrepancy when compared with the GPS-measured geocodes. This may be due to several reasons, of which the resolution of the aerial image is one important factor. In addition, in our study, some of the homes could not be accurately identified in the aerial images since they were covered and surrounded by trees and green spaces. In spite of these limitations, the smartphone-assisted method still offered significant improvement over the traditional methods, especially for addresses for apartment/condominiums since most automated geocoding methods cannot handle apartment-level information.

Extensive efforts have been devoted to improve automated geocoding, and many methods have been proposed including the manual intervention (Chaput et al., 2002; Goldberg et al., 2008; Ward et al., 2005), re-geocoding with a different geocoder (Lovasi et al., 2007; Zhan et al., 2006), and imputation or pseudocoding (Boscoe, 2008; Henry and Boscoe, 2008; Strickland et al., 2007). However, all these methods focused on improving spatial data quality after the data collections. The proposed smartphone-assisted method integrates the aerial imagebased manual corrections to the data collections, thus making it possible to prospectively collect and geocode addresses, to verify the geocoded data during data collections, which is particularly important.

Previous studies have suggested an error rate of $10 \%$ and a missing rate of $5 \%$ of self-reported addresses in public health surveillance datasets (Zinszer et al., 2010). Such errors and missing data can be caused by both participants and administrative staff. Participants may accidentally skip or report a wrong address due to many reasons such as privacy concerns and recall errors. On the other hand, staff may make data-entry and processing mistakes. Importantly, the automated geocoding method may sometimes fail to identify such errors and even assign a false-matched geocode. Unfortunately, it is hard to detect such errors in large datasets and there is no existing validation tool to identify and fix these errors in the data collection process. Such errors are therefore almost impossible to correct once the data collection has been completed. However, this proposed smartphone-assisted method can avoid these issues during the process of data collection with participants' involved verification, real-time of geocoding and aerial image/map-assisted real time search. This proposed method can easily be integrated into many data collection systems and so obtain highquality spatial data. Integrations of this method into data collection systems will transfer the efforts of geocoding from the data collectors to the participants, making it feasible for data collection in large health studies or electronic health records such as vital statistics birth records. It will also allow participants to interact with this geocoding system directly offering an unprecedented use of street maps, satellite images and street views to reduce missing records as well as to improve positional accuracy. Indeed, participants have more local knowledge than GIS technicians and can accurately verify and find the locations of their addresses on maps/aerial images. Therefore, the use of this method for spatial data collection has a great potential with respect to improving spatial data quality.
Several limitations of this study should be noted. First, this is a pilot study that has a relatively small sample size and focused on only one county. Additionally, the smartphone-assisted method was conducted by researchers. Ideally, residents may provide more accurate geocoding information using the system, as they are more familiar with the neighbourhood, especially when the home cannot be directly identified in the image. Furthermore, measurement errors may exist for the reference method using GPS receiver since we were not able to enter the participants' homes.

\section{Conclusions}

With respect to the vital statistics birth record dataset, studies relying on automated geocoding may suffer from potential differential bias. Addresses referring to the housing apartment or condominium type and addresses located in rural areas are more likely to have greater positional errors. The smartphone-assisted method may substantially improve positional accuracy in geocoding, which has the potential to be used as a spatial data collection tool to further improve spatial data quality.

\section{References}

Anthopolos R, Kaufman JS, Messer LC, Miranda ML. 2014. Racial residential segregation and preterm birth: built environment as a mediator. Epidemiology 25:397-405.

Baltsavias EP, 1993. Integration of ortho-images in GIS. In: Proceedings of the Optical Engineering and Photonics in Aerospace Sensing, International Society for Optics and Photonics, pp 314-24.

Bonner MR, Han D, Nie J, Rogerson P, Vena JE, Freudenheim JL, 2003. Positional accuracy of geocoded addresses in epidemiologic research. Epidemiology 14:408-12.

Boscoe F, 2008. The science and art of geocoding: tips for improving match rates and handling unmatched cases in analysis. In: Rushton G, Armstrong MP, Gittler J, Greene BR, Pavlik CE, West MM, Zimmerman D, eds. Geocoding health data: the use of geographic codes in cancer prevention and control, research and practice. CRC Press, Boca Raton, FL, USA, pp 95-110.

Boulos MN, 2005. Web GIS in practice iii: creating a simple interactive map of England's strategic health authorities using google maps API, Google Earth kml, and Msn virtual earth map control. Int J Health Geogr 4:22.

Cayo MR, Talbot T0, 2003. Positional error in automated geocoding of residential addresses. Int $\mathrm{J}$ Health Geogr 2:10.

Chaput EK, Meek JI, Heimer R, 2002. Spatial analysis of human granulocytic ehrlichiosis near Lyme, Connecticut. Emerg Infect Dis 8:943-8.

Conzelmann CP, Sleavin W, Couvillion B, 2005. Using geospatial technology to process 911 calls after hurricanes Katrina and Rita. In: Farris GS, Smith GJ, Crane MP, Demas CR, Robbins LL, Lavoie DL, eds. Science and the storms: the USGS Response to the Hurricanes of 2005. U.S. Geological Survey, Reston, VA, USA, pp 21-5.

Dadvand P, Sunyer J, Basagaña X, Ballester F, Lertxundi A, FernándezSomoano A, Estarlich M, García-Esteban R, Mendez MA, Nieuwenhuijsen MJ, 2012. Surrounding greenness and pregnancy outcomes in four spanish birth cohorts. Environ Health Persp 120:1481-7. 
Frizzelle BG, Evenson KR, Rodriguez DA, Laraia BA, 2009. The importance of accurate road data for spatial applications in public health: customizing a road network. Int J Health Geogr 8:24.

Goldberg DW, Cockburn MG, 2012. The effect of administrative boundaries and geocoding error on cancer rates in California. Spat Spatiotemporal Epidemiol 3:39-54.

Goldberg DW, Wilson JP, Knoblock CA, Ritz B, Cockburn MG, 2008. An effective and efficient approach for manually improving geocoded data. Int J Health Geogr 7:60.

Google, 2015. Google maps developer documentation. Available from: https://developers.google.com/maps/documentation/

Gordian ME, Haneuse S, Wakefield J, 2006. An investigation of the association between traffic exposure and the diagnosis of asthma in children. J Expo Sci Environ Epidemiol 16:49-55.

Griffith DA, Millones M, Vincent M, Johnson DL, Hunt A, 2007. Impacts of positional error on spatial regression analysis: a case study of address locations in Syracuse, New York. Trans GIS 11:655-79.

Henry KA, Boscoe FP, 2008. Estimating the accuracy of geographical imputation. Int J Health Geogr 7:3.

Hild H, Fritsch D, 1998. Integration of vector data and satellite imagery for geocoding. Int Arch Photogr Rem Sens 32:246-51.

Hu H, Ha S, Henderson BH, Warner TD, Roth J, Kan H, Xu X, 2015. Association of atmospheric particulate matter and ozone with gestational diabetes mellitus. Environ Health Persp 123:853-9.

Hu H, Ha S, Roth J, Kearney G, Talbott EO, Xu X, 2014. Ambient air pollution and hypertensive disorders of pregnancy: a systematic review and meta-analysis. Atmos Environ 97:336-45.

Hurley SE, Saunders TM, Nivas R, Hertz A, Reynolds P, 2003. Post office box addresses: a challenge for geographic information systembased studies. Epidemiology 14:386-91.

Hystad P, Davies HW, Frank L, Van Loon J, Gehring U, Tamburic L, Brauer M, 2014. Residential greenness and birth outcomes: rvaluating the influence of spatially correlated built-environment factors. Environ Health Persp 122:1095-102.

Jacquez GM. 2012. A research agenda: does geocoding positional error matter in health gis studies? Spat Spatiotemporal Epidemiol 3:716.

Jacquez GM, Rommel R, 2009. Local indicators of geocoding accuracy (liga): theory and application. Int J Health Geogr 8:60.

James G, Witten D, Hastie T, Tibshirani R, 2013. An introduction to statistical learning. Springer, Amsterdam, The Netherlands.

Krieger N, Waterman P, Lemieux K, Zierler S, Hogan JW, 2001. On the wrong side of the tracts? Evaluating the accuracy of geocoding in public health research. Am J Publ Health 91:1114.

Lovasi GS, Weiss JC, Hoskins R, Whitsel EA, Rice K, Erickson CF, 2007. Comparing a single-stage geocoding method to a multi-stage geocoding method: how much and where do they disagree? Int $\mathrm{J}$ Health Geogr 6:12.

McLafferty S, Freeman VL, Barrett RE, Luo L, Shockley A, 2012. Spatial error in geocoding physician location data from the AMA physician masterfile: implications for spatial accessibility analysis. Spat Spatiotemporal Epidemiol 3:31-8.

Metcalfe A, Lail P, Ghali WA, Sauve RS, 2011. The association between neighbourhoods and adverse birth outcomes: a systematic review and meta analysis of multi level studies. Paediatr Perinat Ep 25:236-45.

Miranda ML, Messer L, Kroeger GL, 2012. Associations between the quality of the residential built environment and pregnancy outcomes among women in North Carolina. Environ Health Persp 120:471-7.
Oliver MN, Matthews KA, Siadaty M, Hauck FR, Pickle LW, 2005. Geographic bias related to geocoding in epidemiologic studies. Int J Health Geogr 4:29.

Richards TB, Croner CM, Rushton G, Brown CK, Fowler L, 1999. Information technology: geographic information systems and public health: mapping the future. Publ Health Rep 114:359.

Sapkota A, Chelikowsky AP, Nachman KE, Cohen AJ, Ritz B, 2012. Exposure to particulate matter and adverse birth outcomes: a comprehensive review and meta-analysis. Air Qual Atmos Health 5:369-81.

Schootman M, Sterling DA, Struthers J, Yan Y, Laboube T, Emo B, 2007. Positional accuracy and geographic bias of four methods of geocoding in epidemiologic research. Ann Epidemiol 17:464-70.

Shah PS, Balkhair T, 2011. Air pollution and birth outcomes: a systematic review. Environ Int 37:498-516.

Stieb DM, Chen L, Eshoul M, Judek S, 2012. Ambient air pollution, birth weight and preterm birth: a systematic review and meta-analysis. Environ Res 117:100-11.

Strand LB, Barnett AG, Tong S, 2011. The influence of season and ambient temperature on birth outcomes: a review of the epidemiological literature. Environ Res 111:451-62.

Strickland MJ, Siffel C, Gardner BR, Berzen AK, Correa A, 2007. Quantifying geocode location error using gis methods. Environ Health 6:1-8.

Vrijheid M, Martinez D, Manzanares S, Dadvand P, Schembari A, Rankin J, 2011. Ambient air pollution and risk of congenital anomalies: a systematic review and meta-analysis. Environ Health Persp 119:598-606.

Ward MH, Nuckols JR, Giglierano J, Bonner MR, Wolter C, Airola M, Mix W, Colt JS, Hartge P, 2005. Positional accuracy of two methods of geocoding. Epidemiology 16:542-7.

Whitsel EA, Quibrera PM, Smith RL, Catellier DJ, Liao D, Henley AC, 2006. Accuracy of commercial geocoding: assessment and implications. Epidemiol Persp Innov 3:8.

Wing MG, 2008. Consumer-grade global positioning systems (GPS) receiver performance. J Forestry 106:185-90.

Wu J, Funk TH, Lurmann FW, Winer AM, 2005. Improving spatial accuracy of roadway networks and geocoded addresses. Trans GIS 9:585-601.

Zandbergen PA, 2007. Influence of geocoding quality on environmental exposure assessment of children living near high traffic roads. BMC Publ Health 7:37.

Zandbergen PA, 2008. Positional accuracy of spatial data: non normal distributions and a critique of the national standard for spatial data accuracy. Trans GIS 12:103-30.

Zandbergen PA, Ignizio DA, Lenzer KE, 2011. Positional accuracy of tiger 2000 and 2009 road networks. Trans GIS 15:495-519.

Zhan FB, Brender JD, De Lima I, Suarez L, Langlois PH, 2006. Match rate and positional accuracy of two geocoding methods for epidemiologic research. Ann Epidemiol 16:842-9.

Zimmerman DL, Fang X, Mazumdar S, 2008. Spatial clustering of the failure to geocode and its implications for the detection of disease clustering. Stat Med 27:4254-66.

Zinszer K, Jauvin C, Verma A, Bedard L, Allard R, Schwartzman K, de Montigny L, Charland K, Buckeridge DL, 2010. Residential address errors in public health surveillance data: a description and analysis of the impact on geocoding. Spat Spatiotemporal Epidemiol 1:163-8. 